\title{
Efficient Amination of Heteroaryl and Aryl Halides Using [(CyPF-t-Bu)PdCl $\left.\mathrm{I}_{2}\right]$
}
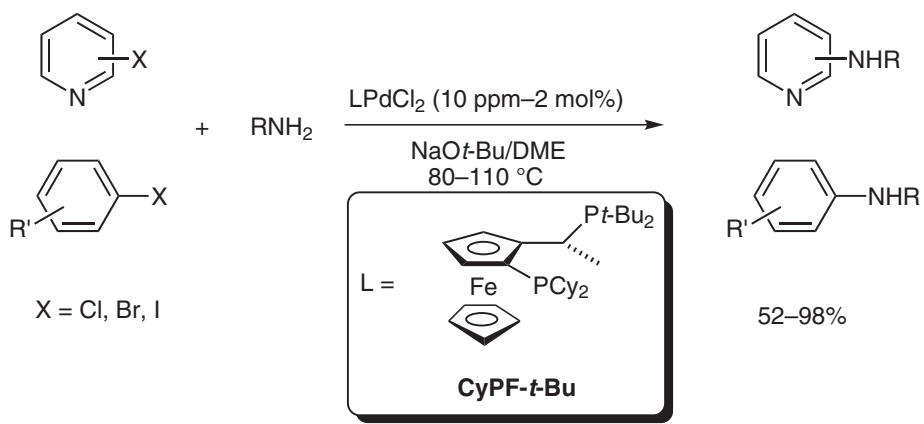

$52-98 \%$

Selected examples:

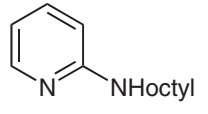

$92 \%$<smiles>COc1ccccc1NCC(C)C</smiles>

$98 \%$<smiles>[AlH2]Nc1ccc2ccccc2n1</smiles>

$85 \%$<smiles>O=C([O-])ONc1ccc([N+](=O)[O-])cc1</smiles>

$85 \%$<smiles>c1cncc(NC2CCCCC2)c1</smiles>

$88 \%$<smiles>CCOC(=O)c1ccc(NC(C)CC)cc1</smiles>

$71 \%$

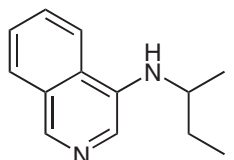

$96 \%$

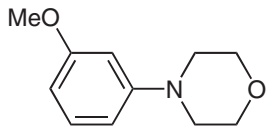

$89 \%$
Significance: $\left[(\mathrm{CyPF}-t-\mathrm{Bu}) \mathrm{PdCl}_{2}\right]$ has been found to be a highly efficient, air- and moisture-resistant catalyst for the aminative coupling of heteroaryl chlorides, bromides and iodides to a variety of primary amines. The required catalyst loading is extremely low, most reactions give a high yield of product with $0.001-0.05$ mol\% of catalyst. A wide range of functional groups is tolerated in this amination reaction.
Comment: [(CyPF-t-Bu) $\mathrm{PdCl}_{2}$ ] is not only air- and moisture-stable, but also a single-component catalyst, avoiding the need for complexation of metal and ligand under higher concentrations prior to the addition of the substrates. The catalyst shows an excellent functional group compatibility and requires about two orders of magnitude less loadings than other catalyst systems. The broad scope of this reaction as well as the high tolerance for functional groups such as cyano, keto or even nitro makes this procedure a very useful tool for amination reactions. 